\title{
Genetic and physiological basis for antibody production by Kluyveromyces marxianus
}

Yumiko Nambu-Nishida ${ }^{1,2}, K_{\text {Keiji Nishida }}^{3}$, Tomohisa Hasunuma ${ }^{3}$ and Akihiko Kondo $2,3^{*}$ (D)

\begin{abstract}
Kluyveromyces marxianus is a thermotolerant, crabtree-negative yeast, which preferentially directs metabolism (e.g., from the tricarboxylic acid cycle) to aerobic alcoholic fermentation. Thus $K$. marxianus has great potential for engineering to produce various materials under aerobic cultivation conditions. In this study, we engineered K. marxianus to produce and secrete a single-chain antibody (scFv), a product that is highly valuable but has historically proven difficult to generate at large scale. scFv production was obtained with strains carrying either plasmid-borne or genomically integrated constructs using various combinations of promoters $\left(\mathrm{P}_{\mathrm{MDH} 1}\right.$ or $\left.\mathrm{P}_{\mathrm{ACO}}\right)$ and secretion signal peptides (KmINUss or Sca-MFss). As the wild-type K. marxianus secretes endogenous inulinase predominantly, the corresponding INU1 gene was disrupted using a Clustered Regularly Interspaced Short Palindromic Repeat (CRISPR) - associated protein (CRISPR-Cas9) system to re-direct resources to scFv production. Genomic integration was used to replace INU1 with sequences encoding a fusion of the INU1 signal peptide to SCFv; the resulting construct yielded the highest scFv production among the strains tested. Optimization of growth conditions revealed that scFv production by this strain was enhanced by incubation at $30^{\circ} \mathrm{C}$ in xylose medium containing $200 \mathrm{mM} \mathrm{MgSO}_{4}$. These results together demonstrate that $K$. marxianus has the potential to serve as a host strain for antibody production.
\end{abstract}

Keywords: Kluyveromyces marxianus, Single-chain antibody (scFv), INU1, Inulinase, $\mathrm{MgSO}_{4}$

\section{Introduction}

Production of biopharmaceuticals requires the difficult choice of a host cell capable of generating the desired product in an active and safe form, devoid of unwanted modification or contamination. Additionally, some biopharmaceuticals such as antibodies have proven difficult to express at high levels. Chinese hamster ovary $(\mathrm{CHO})$ cells and yeasts are the major hosts that have been engineered to produce biopharmaceutical products, including antibodies (Maccani et al. 2014). As mammalian cells, $\mathrm{CHO}$ cells produce mammalian-derived proteins in an active form, bearing appropriate modifications such as glycosylation. However, the development of stable cell

\footnotetext{
*Correspondence: akondo@kobe-u.ac.jp

2 Department of Chemical Science and Engineering, Graduate School of Engineering, Kobe University, 1-1 Rokkodai-cho, Nada-ku, Kobe, Hyogo 657-8501, Japan

Full list of author information is available at the end of the article
}

lines takes very long times (6-12 months), and the cost of cell culture is very high (Lai et al. 2013). Bacterial expression host such as Escherichia coli provides much cheaper option, while proteins that require eukaryotic posttranslational modifications are not suitable (Swartz 2001; Jevševar et al. 2005). Yeast cells such as Pichia pastoris may provide much faster and cheaper ways of production (Çelik and Çalık 2012); while this yeast can be engineered to serve as a suitable hosts, highly complex proteins such as antibodies can be difficult to express efficiently in this system (Nielsen 2013). In the previous study, we have shown that Kluyveromyces marxianus grow faster than Saccharomyces cerevisiae at wider range of temperature (Nambu-Nishida et al. 2017). K. marxianus also does not show obligate ethanol production aerobically and thus is expected to be engineered to produce various substrates (Wagner and Alper 2016). 
Due to difficulties in expression, secretion, and posttranslational modification, antibodies intended for clinical use remain a challenge to produce in a cost-effective manner (Buckholz and Gleeson 1991; Huang et al. 2014). Single-chain $\mathrm{Fv}$ antibody ( $\mathrm{scFv}$ ) is one of the most useful forms of antibody, consisting of a single polypeptide in which the variable regions of the heavy $\left(\mathrm{V}_{\mathrm{H}}\right)$ and light $\left(V_{L}\right)$ chain domains are fused by a short, flexible linker; the resulting product has a molecular weight of approximately $30 \mathrm{kDa}$ (Damasceno et al. 2004). Unlike large immunoglobulins (IgGs), scFv proteins have demonstrated rapid tumor penetration (Yokota et al. 1992). A prototypical $\mathrm{scFv}$ is the anti-chicken (anti-hen) egg white lysozyme antibody (HyHEL-10), which has been used for the precise analysis of antigen-antibody interactions (Tsumoto et al. 1997).

The non-conventional yeast Kluyveromyces marxianus can grow on various sugars (glucose, xylose, fructose, sucrose, inulin, etc.) (Fonseca et al. 2008; Lane and Morrissey 2010; Lertwattanasakul et al. 2011). K. marxianus is known to secrete proteins such as inulinase into the culture medium at high levels (Rouwenhorst et al. 1990; $\mathrm{Hu}$ et al. 2012). Engineering of K. marxianus for protein production has been reported for both endogenous and heterologous enzymes (Raimondi et al. 2013; Hong et al. 2007). However, there are to date (to our knowledge) no reports on secretory antibody production in $K$. marxianus.

The K. marxianus NBRC1777 strain recently has been shown to exhibit rapid growth and adaptability to a wide range of temperatures (from 5 to $45{ }^{\circ} \mathrm{C}$ ). Additionally, comprehensive genome engineering tools recently have been introduced for use in this strain, including a Clustered Regularly Interspaced Short Palindromic Repeat (CRISPR)-associated protein (CRISPR-Cas9) system and deaminase-mediated base editing Target-AID (Nambu-Nishida et al. 2017). NBRC1777 is expected to be of use for various bio-production applications, including the secretion of high-value proteins.

In the present study, we introduced $K$. marxianus NBRC1777 as a novel host for scFv production. Several parameters were examined, including the type of secretion signal and growth conditions such as temperature, carbon source, and medium. Genetic backgrounds that affect protein production or secretion also were studied.

\section{Materials and methods}

Strains and culture conditions

The $K$. marxianus and $S$. cerevisiae strains used in this study are listed in Table 1. E. coli strain DH5 $\alpha$ (Toyobo,

Table 1 Plasmids and strains used in this study

\begin{tabular}{|c|c|c|}
\hline Plasmids and strains & Genotype & References \\
\hline \multicolumn{3}{|l|}{ Plasmids } \\
\hline E02-012 & $\mathrm{KmP}_{\text {MDH1_KmINU1ss_scFv_T }}$ TDH3 $_{1}, \mathrm{KmARS7}$, KmCEN D, kanMX, ori, and AmpR & This study \\
\hline E02-014 & $\mathrm{KmP}_{\text {ACO1_KmINU1ss_sCFv_T }}{ }_{\text {TDH3 }}, \mathrm{KmARS7}, \mathrm{KmCEN} \mathrm{D}$, kanMX, ori, and AmpR & This study \\
\hline E02-020 & $\mathrm{KmP}_{M D H 1}$ Sca-MFss_scFv_T $T_{T D H 3}, \mathrm{KmARS7}, \mathrm{KmCEN} \mathrm{D,} \mathrm{kanMX}$, ori, and AmpR & This study \\
\hline E02-022 & $\mathrm{KmP}_{\text {ACO1_Sca-MFsS_sCFv_T }}{ }_{T D H 3}, \mathrm{KmARS7}$, KmCEN D, kanMX, ori, and AmpR & This study \\
\hline Cas9_Base & $\mathrm{SCP}_{P D C 1}{ }_{\text {Cas9_T }} \mathrm{TDH}_{3}, \mathrm{KmARS7}, \mathrm{KmCEN} \mathrm{D,} \mathrm{kanMX}$, ori, and AmpR & Nambu-Nishida et al. (2017) \\
\hline E02-025 & $\begin{array}{l}\mathrm{KmP}_{\text {SNR52_target_gRNA-1_sgRNA_T }} \mathrm{T}_{\text {sup4 }} \text { cassette and KmP } \\
\text { cassette in Cas9_Base }\end{array}$ & This study \\
\hline E02-026 & $\begin{array}{l}\mathrm{KmP}_{\text {SNR52_target_gRNA-1_sgRNA_T }} \text { sup4 }_{\text {cassette and }} \mathrm{KmP}_{\text {SNR52_target_gRNA-2_sgRNA_T}} \text { sup4 } \\
\text { cassette in Cas9_Base }\end{array}$ & This study \\
\hline \multicolumn{3}{|l|}{ Strains } \\
\hline $1(\mathrm{NBRC} 1777)$ & Wild-type (WT) & $\begin{array}{l}\text { NITE } \\
\text { Biological Resource Center, Japan }\end{array}$ \\
\hline Nej $1^{\circ}$ & Nej1 disrupted by C to T point mutation at posision 13 & Nambu-Nishida et al. (2017) \\
\hline $\operatorname{Dn} / 4^{\circ}$ & Dn/4 disrupted by G to A point mutation at posision 44 & Nambu-Nishida et al. (2017) \\
\hline $2(\mathrm{Km02-026)}$ & WT/E02-012 & This study \\
\hline $3(\mathrm{Km02-032)}$ & WT/E02-014 & This study \\
\hline $4(\mathrm{Km02-050)}$ & WT/E02-020 & This study \\
\hline $5(\mathrm{Km02-056)}$ & WT/E02-022 & This study \\
\hline$\Delta$ inul (Km02-063) & Nej1\% 1 inu1 & This study \\
\hline $6(\mathrm{Km02-064)}$ & Nej1\%inu1::.P INU1_SCFV $_{\text {IN }}$ & This study \\
\hline $7(\mathrm{Km02-065)}$ & Dnl4\%inu $1:: \mathrm{P}_{\text {INU1_SCFV }}$ & This study \\
\hline $8(\mathrm{Km02-066)}$ & Nej1\%inu1::/E02-020 & This study \\
\hline BY4741 & MATa his $3 \triangle 1$ leu $2 \Delta 0$ met $15 \Delta 0$ ura $3 \Delta 0$ & ATCC (Brachmann et al. 1998) \\
\hline
\end{tabular}


Osaka, Japan) was used for vector construction and cloning. E. coli and yeast cells were grown as described previously (Nambu-Nishida et al. 2017). Genomic DNA from S. cerevisiae BY4741 was used as a template to amplify $\alpha-\mathrm{MF}(\mathrm{Sc} \alpha-\mathrm{MF})$ coding fragment.

\section{INU1 gene disruption}

The inu1 gene-disrupted strain and homologous recombination strains were generated using the CRISPR-Cas9

Table 2 Target sequences used in this study

\begin{tabular}{ll}
\hline Name & Sequence $\left(\mathbf{5}^{\prime} \boldsymbol{\rightarrow} \mathbf{3}^{\prime}\right)$ \\
\hline gRNA-1 & TATAAAATGTCGCTGTGACC \\
gRNA-2 & CAACTACAACCGGATACCTG \\
gRNA-3 & ATGGAAGCAAGAGGGAGTAT \\
\hline
\end{tabular}

system. The CRISPR-Cas9 vector plasmid (Cas9_Base) of $K$. marxianus, target sgRNA cassette construction, and methods were as described previously (Nambu-Nishida et al. 2017). The inu1 deletion strain was generated by using a Cas9 plasmid (E02-026) containing gRNA-1 and gRNA-2 target sequences (Table 2 and Fig. 1a).

\section{Replacement of INU1 by integration of a scFv-encoding sequence}

HyHEL-10 scFv (scFv hereafter) amino acid sequence (Additional file 1: Figure S1) was codon optimized for expression in $K$. marxianus. The homologous recombination strain was generated by transforming the recipient strain by the lithium acetate method (Gietz et al. 1992), using $10 \mu \mathrm{g}$ of Cas9 plasmid (E02-025) containing gRNA-1 and gRNA-3 target sequences (Table 2 and Fig. 1b) and $5 \mu \mathrm{g}$ of the sequence-optimized fragment encoding scFv (Additional file 1: Figure S2). The

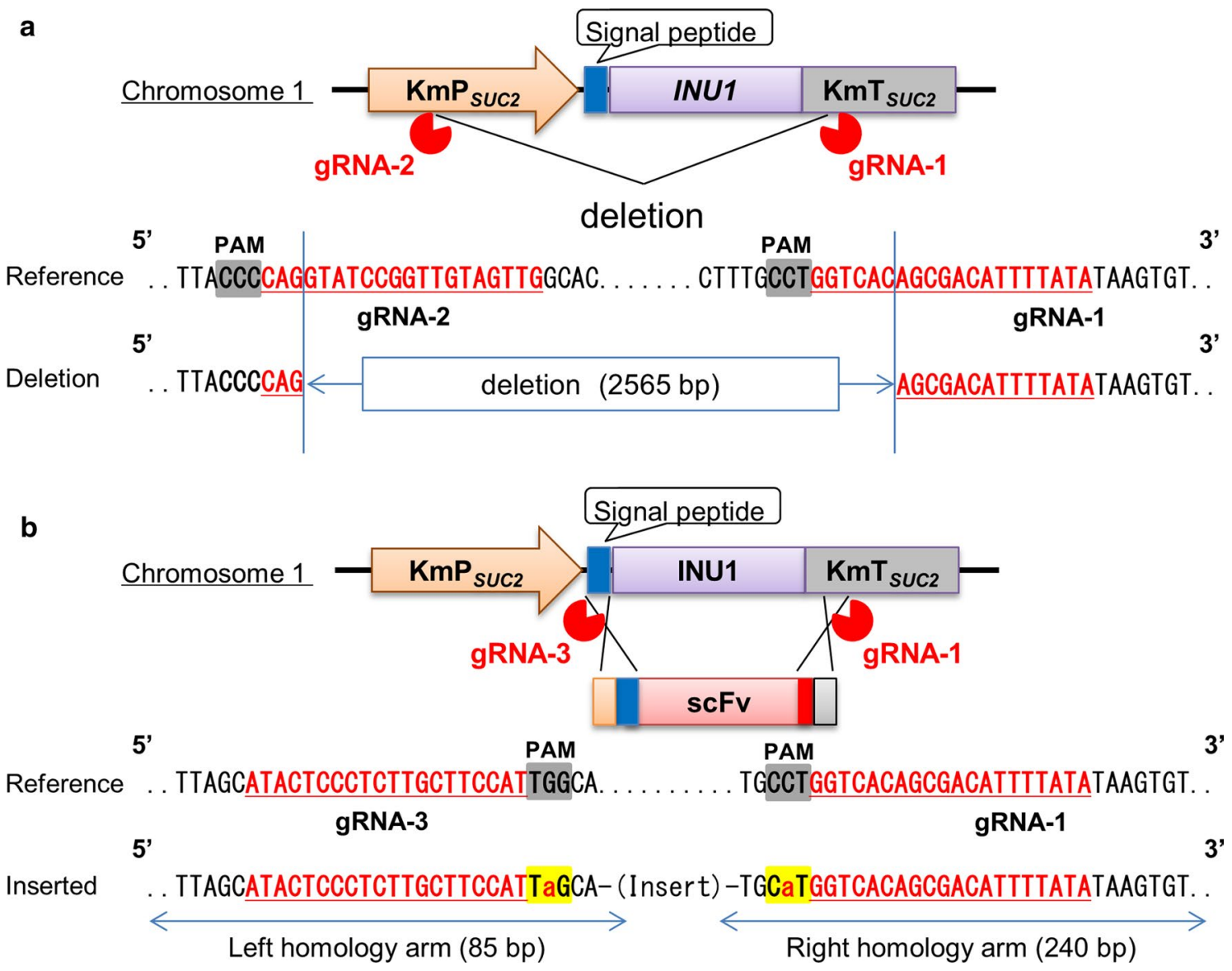

Fig. 1 Design of INU1 disruption and replacement. a A schematic of the INU1 locus and its deletion is shown. Reverse complement sequences of target (red) and PAM (shadowed) are shown on the reference sequence. The lower part of the panel shows an alignment of the sequence from the deletion strain with the sequence of the wild-type locus. b A schematic of the INU1 replacement by a fragment encoding scFv is shown. The mutated PAM sequence and its reverse complement sequence are highlighted in yellow. Mutated bases are indicated as small red letters. The scFvencoding fragment also encodes the INU1 secretion signal peptide (blue box) and a 6-histidine tag (red box) in-frame with the expressed ORF 
transformed cells were plated on YPD containing the appropriate selection reagent $(100 \mu \mathrm{g} / \mathrm{mL}$ G418).

\section{Verification of genome-edited cells}

Transformants generated using the CRISPR-Cas9 system were screened by colony PCR using the primer pair P_Km01-010+P_Km01-010-011 (Additional file 1: Table S1). DNA sequence of the resulting amplicon was confirmed by sequencing using a 3130xL Genetic Analyzer (Applied Biosystems, CA, USA). The transformant cells were grown without selection reagents to isolate a clone that dropped the Cas9 plasmid.

\section{Construction of scFv expression plasmids}

The constructed plasmids are listed in Table 1. Plasmid E02-014, which includes KmARS7, KmCEN-D, the scFvencoding fragment, $\mathrm{KmP}_{A C O 1}$, and the $\mathrm{kanMX}$ selectable marker (which provides G418 resistance) is shown as an example (Additional file 1: Figure S3).

Constructs incorporated either the $\mathrm{P}_{M D H 1}\left(\mathrm{KmP}_{M D H 1}\right)$ (Additional file 1: Figure S4) or $\mathrm{P}_{A C O 1}\left(\mathrm{KmP}_{A C O 1}\right)$ (Additional file 1: Figure S5) promoters from $K$. marxianus. Constructs also incorporated sequences encoding either the secretory signal sequence from inulinase (KmINUss) from $K$. marxianus (Bergkamp et al. 1993) or that from Sc $\alpha$-MFss from S. cerevisiae (Melorose et al. 1986). Fragments carrying the desired promoter fragment and encoding the desired signal sequence were inserted into the NheI or Sbfl/BamHI sites of the E02-014 plasmid using In-fusion cloning (Takara Bio, Shiga, Japan). The resulting scFv expression plasmids were transformed into K. marxianus NBRC1777 or the inu1 deletion strain by the transformation and selection methods noted above.

\section{SDS-PAGE and immunoblot analysis}

To analyze protein production, soluble proteins in the spent culture medium were separated on a SDSpolyacrylamide $12.5 \%$ gel (ATTO, Tokyo, Japan) and stained with Bio-Safe Coomassie Stain (Bio-Rad, Hercules, CA). MagicMark ${ }^{\mathrm{TM}}$ XP Western Protein Standard (Thermo Fisher Scientific Inc., MA, USA) was included as the molecular weight standard. For western blotting, proteins were transferred to a polyvinylidene fluoride (PVDF) membrane (EDM Millipore, Billerica, MA, USA) by electroblotting. The membrane then was blocked by incubation for $1 \mathrm{~h}$ at room temperature with Blocking One (Nacalai tesque, Kyoto, Japan), followed by washing with TBST (0.1 M Tris-HCl, $0.15 \mathrm{M} \mathrm{NaCl}, 0.05 \%$ Tween 20). The membrane then was incubated for $1 \mathrm{~h}$ with the primary antibody, rabbit anti-6-His Antibody Affinity Purified (Bethyl Laboratories, TX, USA) diluted 1:5000, followed by washing with TBST and incubation for $1 \mathrm{~h}$ with the secondary antibody, Peroxidase AffiniPure Goat
Anti-Rabbit IgG $(\mathrm{H}+\mathrm{L})$ (Jackson ImmunoResearch Laboratories, PA, USA) diluted 1:10,000. Protein bands were detected by ImmunoStar Zeta (Wako, Osaka, Japan).

\section{Enzyme-linked immunosorbent assay (ELISA)}

Strains were cultured in YPD or YPX $(10 \mathrm{~g} / \mathrm{L}$ yeast extract, $20 \mathrm{~g} / \mathrm{L}$ peptone, and $20 \mathrm{~g} / \mathrm{L}$ xylose) supplemented with $100 \mathrm{mM}$ sodium phosphate buffer, $\mathrm{pH}$ 6.0, and selective agent for plasmid-bearing strains in the absence or presence of $200 \mathrm{mM} \mathrm{MgSO}$ selective medium. Culturing was performed in 96-well deep-well plates at 20 or $30{ }^{\circ} \mathrm{C}$ with shaking at $1200 \mathrm{rpm}$.

For ELISA, a MaxiSorp plate (Thermo Fisher Scientific Inc.) was coated by distribution of $50 \mu \mathrm{L}$ per well of lysozyme formulated at $1 \mu \mathrm{M}$ in $1 \times$ phosphate-buffered saline [PBS $(10 \times$ stock), Nacalai Tesque] followed by overnight incubation at $4{ }^{\circ} \mathrm{C}$. The plate then was blocked at $25{ }^{\circ} \mathrm{C}$ for $1 \mathrm{~h}$ with the blocking solution (ImmunoBlock, DS Pharma Biomedical, Japan) diluted 1:5 in water. The plate was washed three times with PBST $(1 \times$ PBS supplemented with $0.1 \%$ Tween-20 and $2 \%$ blocking solution). Supernatants (spent medium) from cultures were diluted fivefold in PBST containing 2\% ImmunoBlock and distributed at $50 \mu \mathrm{L} /$ well. All ELISAs included a blank consisting of $70 \mu \mathrm{L}$ PBST containing 2\% ImmunoBlock. Following incubation at $25^{\circ} \mathrm{C}$ for $1 \mathrm{~h}$, the plate was washed as above, and antibody (Anti-His-tag mAb-HRPDirecT, MLB, Nagoya, Japan), diluted 1:8000 in PBST, was distributed at $50 \mu \mathrm{L} /$ well. The plate was incubated at $25^{\circ} \mathrm{C}$ for $1 \mathrm{~h}$ and then washed with PBST as above. Color was developed using TMB 1-Component Microwell Peroxidase Substrate Sure Blue and TMB Stop Solution (KLP Inc, Milford, USA) according to manufacturer's instructions. Activity and growth were then measured as absorbance at $450 \mathrm{~nm}\left(\mathrm{ABS}_{450}\right)$ and $600 \mathrm{~nm}\left(\mathrm{OD}_{600}\right)$, respectively using a SpectraMax Paradigm Multi-Mode Microplate Reader (Molecular Devices Japan, Tokyo, Japan). Relative activity of scFv was obtained by subtracting the value of blank.

\section{Accession numbers}

The codon-optimized scFv-encoding sequence was submitted to the DDBJ/EMBL/GenBank databases under accession number LC369677. The genome sequence of K. marxianus NBRC1777 was in the DDBJ/EMBL/GenBank databases under accession number AP014599 to AP014607 (Inokuma et al. 2015).

\section{Results}

\section{Disruption of INU1 gene by CRISPR-Cas9 system}

Wild-type $K$. marxianus predominantly secretes inulinase (Rouwenhorst et al. 1988; Hu et al. 2012). To facilitate the purification of the heterologous protein and 
re-direct cellular resources for protein production, we deleted the corresponding INU1 gene. A CRISPR-Cas9 vector for $K$. marxianus (Nambu-Nishida et al. 2017) expressing a pair of guide RNAs (gRNA-1 and gRNA-2) flanking the INU1 coding region was constructed and used to transform the parent strain; transformants were then screened for the inu1 mutation (Fig. 1a). For integration of the scFv-encoding sequence at the INU1 locus, we employed strains deficient in the non-homologous end-joining (NHEJ) repair pathway (in this instance, harboring $n e j 1^{\circ}$ or $d n l 4^{\circ}$ null mutations) (Nambu-Nishida et al. 2017) to facilitate homology-directed integration. Another vector expressing a pair of guide RNAs (gRNA-1 and gRNA-3) flanking the INU1 coding region (Fig. 1b) was designed and transformed in combination with an scFv-encoding fragment. The scFv-encoding fragment was flanked with arms (85 and 240 bp for the upstream and downstream sequences, respectively) with homology to the INU1 ORF. PAM sequences of the targets in the arms were mutated to prevent re-cutting after successful integration. Vector-carrying transformant cells were PCR-amplified and subjected to agarose gel electrophoresis (Fig. 2). Sequence analysis of the deletion transformant confirmed that the chromosomal INU1 locus harbored a 2565-bp deletion between the gRNA-2 and gRNA-1 targeting sites, yielding $\Delta i n u 1$ (Km02-063) strain (Fig. 1a). Sequence analysis of the transformants from the gene-replacement experiment confirmed that the INU1 ORF had been replaced by sequences encoding $\mathrm{scFv}$; two of the resulting constructs were designated strains No. 6 (Km02-064) and No.7 (Km02-065) (Figs. 1b and $3 \mathrm{~b})$. Note that these two strains include $n e j 1^{\circ}$ or $d n l 4^{\circ}$, respectively. Next, the strains were assessed for inulinase secretion.

SDS-PAGE analysis of spent culture medium recovered from the wild-type strain revealed a single major band at approximately $90 \mathrm{kDa}$ (Fig. 3c), consistent with the expected size of inulinase (Hong et al. 2014). Notably, this band was absent in spent medium from cultures of the inu1 constructs, as expected (Fig. 3c).

\section{Expression and secretion of scFv antibody}

For the expression of $\mathrm{scFv}$, various expression cassettes containing combinations of promoters $\left(\mathrm{P}_{M D H 1}, \mathrm{P}_{A C O 1}\right)$ and secretion signal (KmINUss, Sc $\alpha$-MFss) -sequences were introduced, either via plasmid or by genomic integration (Fig. 3a, b). Protein expression and secretion was assessed by immunoblotting of spent growth medium (Fig. 3d). Secretion of scFv was confirmed as the presence of an approximately $30 \mathrm{kDa}$ protein (Damasceno et al. 2004) in the spent growth medium from each of the transformed strains tested (Fig. 3d). These results

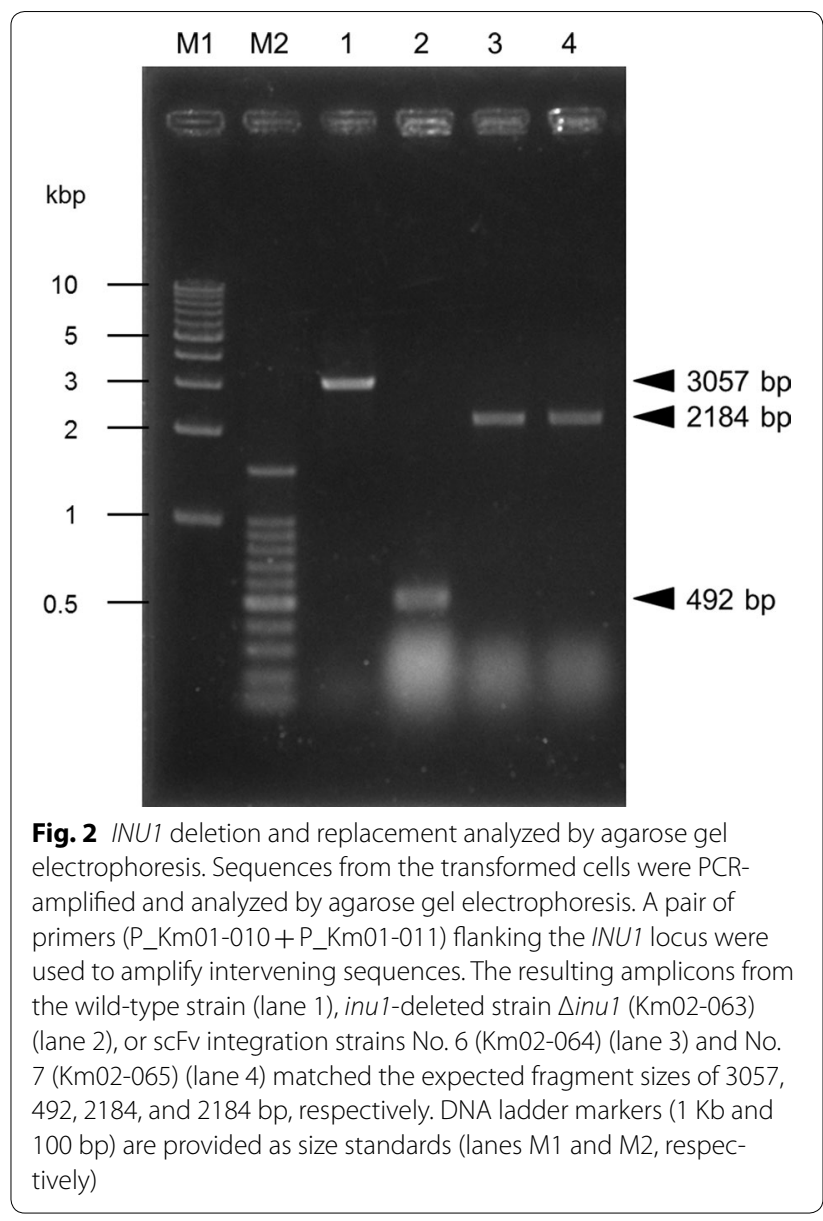

indicated that these promoters and secretion signals functioned in a modular fashion.

\section{Activity of scFv antibody and improved production by magnesium sulfate supplementation}

We next sought to identify growth conditions, including the use of various media, that would yield enhanced expression and secretion of the intact $\mathrm{scFv}$ protein. Cells were grown, with shaking in 96-well deep-well plates, at temperatures of 20 or $30^{\circ} \mathrm{C}$ in YPD or YPX medium in the presence or absence of various supplements and subjected to ELISA to detect the presence of intact secreted $\mathrm{scFv}$. In this context, ELISA measured the immunoreactivity of $\mathrm{scFv} . \mathrm{MgSO}_{4}$ was found to have substantial impact on the antibody production in $K$. marxianus (Fig. $4 \mathrm{a}, \mathrm{b}$ ). At $20{ }^{\circ} \mathrm{C}$, all strains exhibited increased activity when grown in YPD plus $\mathrm{MgSO}_{4}$ (Fig. 4a). At $30{ }^{\circ} \mathrm{C}$, more than tenfold increased activity was observed for strains No. 6 (Km02-064) and No. 7 (Km02-065), both of which harbor constructs introduced by genomic integration, when grown in xylose medium containing $\mathrm{MgSO}_{4}$ (Figs. $3 \mathrm{~b}$ and $4 \mathrm{~b}$ ). Deletion of INU1 yielded about 4.4-fold increase 


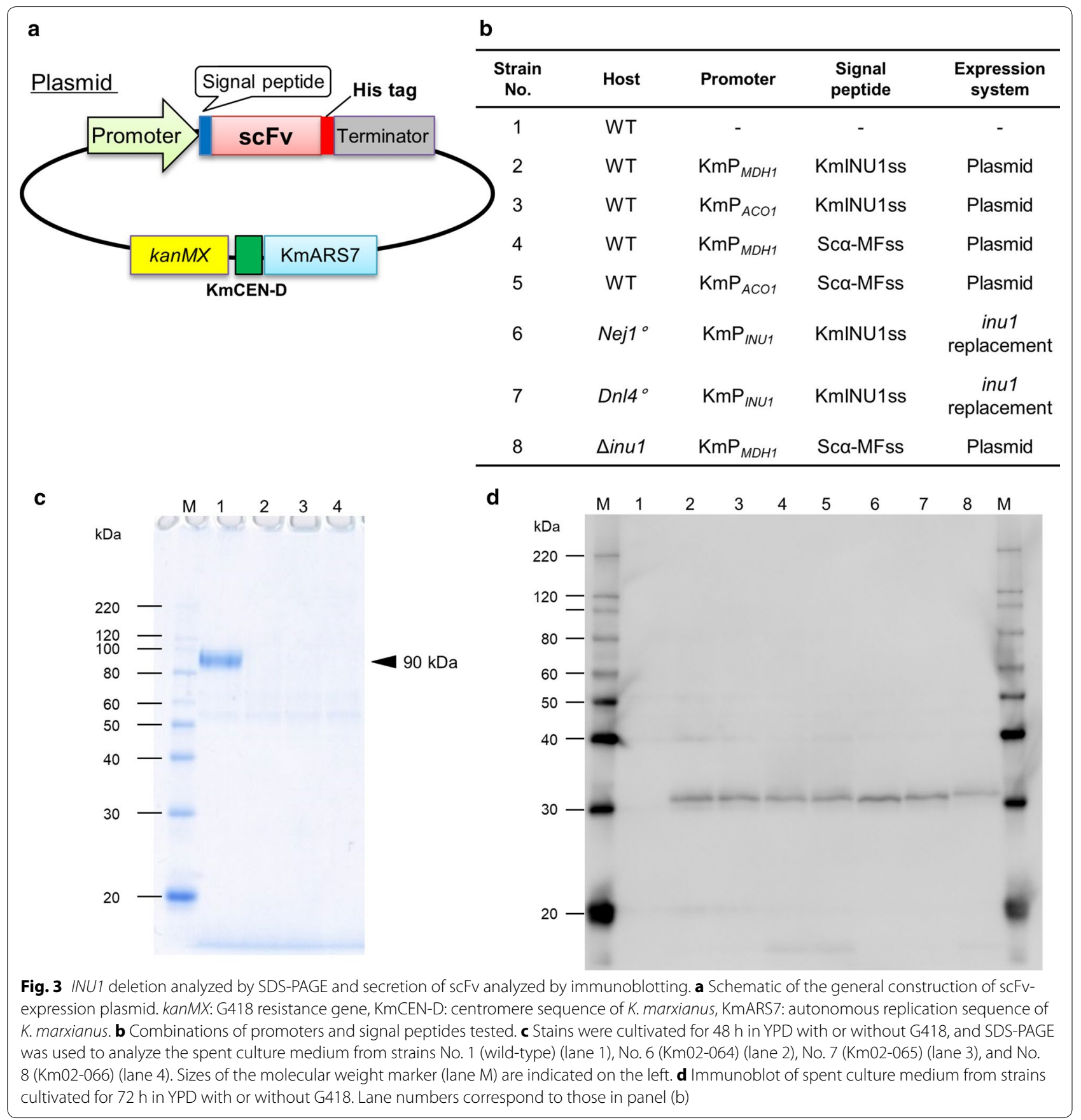

in scFv activity in xylose medium containing $\mathrm{MgSO}_{4}$, when comparing strain No. 4 (Km02-050) (harboring a plasmid-borne construct) and strain No. 8 (Km02-066) (INU1 disruptant harboring a plasmid-borne construction) (Figs. $3 \mathrm{~b}$ and $4 \mathrm{~b})$. The scFv activity $\left(\mathrm{ABS}_{450}\right)$ per cell amount $\left(\mathrm{OD}_{600}\right)$ was calculated and shown in Additional file 1: Figure S6. At $30{ }^{\circ} \mathrm{C}$, the strains No. 6 and No. 7 showed the highest $\mathrm{scFv}$ activity per cell amount in YPD plus $\mathrm{MgSO}_{4}$ (Additional file 1: Figure S6b).

\section{Discussion}

In this study, we demonstrated that $K$. marxianus NBRC1777 can be engineered to express and secrete a single-chain antibody. We showed that secretion of scFv could be changed substantially by use of various genetic constructs and by modification of the growth conditions.

The recently introduced CRISPR-Cas9 and TargetAID genome editing systems (Nambu-Nishida et al. 2017) permit genetic manipulation of organisms that 

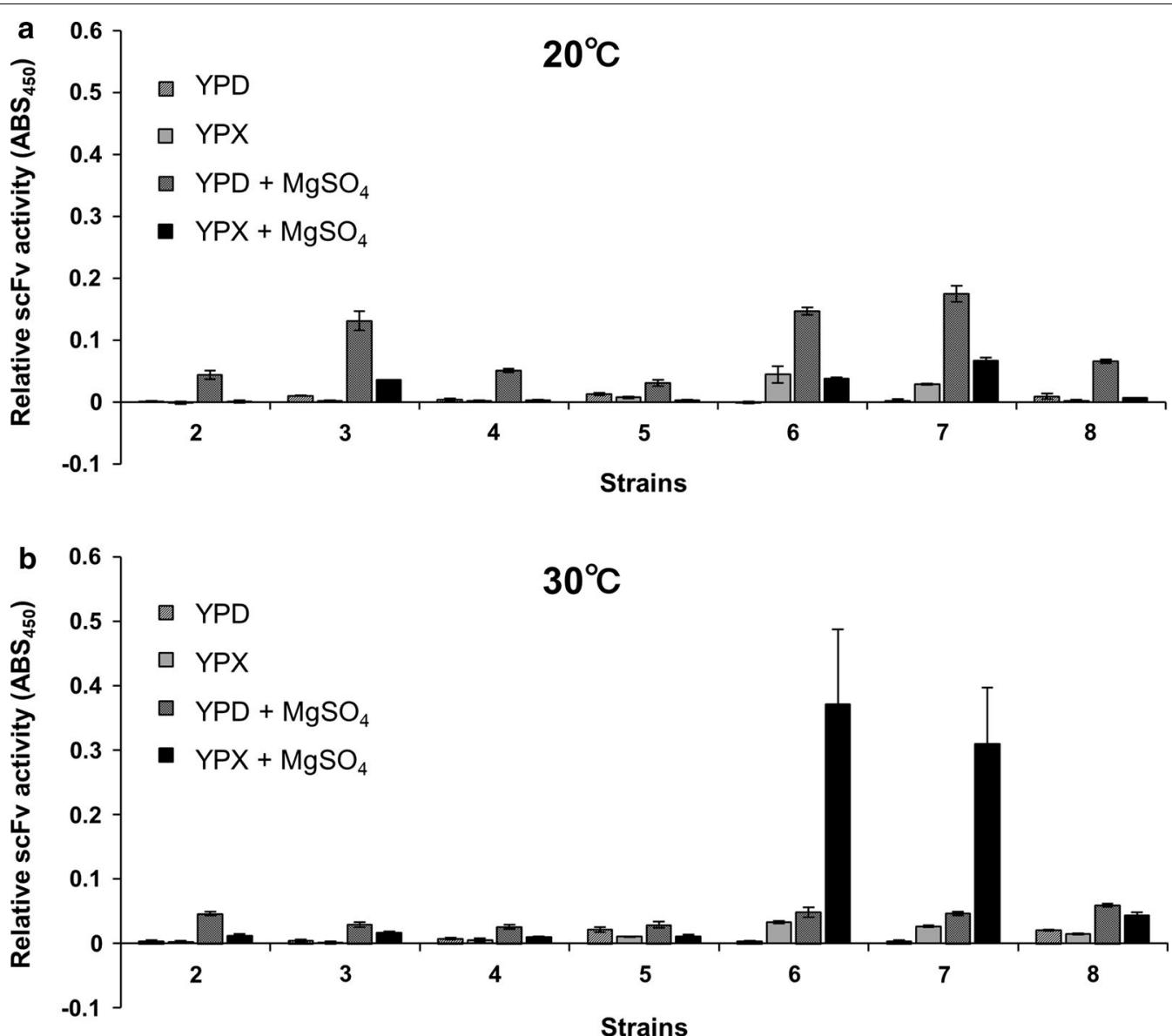

Fig. 4 Immunoreactivity of secreted scFv analyzed by ELISA. Strains were cultured in YPD or YPX in the absence or presence of $\mathrm{MgSO}_{4}$ at $20^{\circ} \mathrm{C}(\mathbf{a})$ or $30^{\circ} \mathrm{C}(\mathbf{b})$. Spent culture medium was harvested at $72 \mathrm{~h}$ and subjected to ELISA using lysozyme as an antigen for scFv. Values are presented as mean \pm SEM from three independent experiments

had previously been underexploited because of a lack of genetic tools. In the present work, a sequence encoding $\mathrm{ScFv}$ was integrated into the INU1 locus without an associated selection marker. This construct allowed robust expression of the integrated gene without a need for continued use of selection reagents. The strains (Nos. 6 and 7) carrying the integrated construct showed dramatic increases in $\mathrm{scFv}$ immunoreactivity compared to strains expressing $\mathrm{scFv}$ via plasmid-borne constructs when grown in YPX plus $\mathrm{MgSO}_{4}$ at $30^{\circ} \mathrm{C}$ (Fig. 4b). This is attributed to either increased expression and secretion or improved quality of the antibody, or both. The higher productivity of $\mathrm{scFv}$ in the strains (Nos. 6 and 7) is attributed to the productivity per cell rather than cell growth. Further work will be needed to determine whether increased expression requires genomic integration in general or at the INU1 locus specifically. It is formally possible that episomal plasmids are not well retained during outgrowth, especially if protein expression creates stress for the host cell.
In our hands, YPX medium induced increased expression from the INU1 promoter but not from the other tested promoters (Fig. 4a, b). As the INU1 product inulinase metabolizes inuline to fructose (Rouwenhorst et al. 1988), INU1 is downregulated in the presence of glucose, the preferred sugar (Jain et al. 2012). Moreover, INU1 gene expression is known to be up-regulated when fructose replaces glucose as a sugar source (Schabort et al. 2016), and the INU1 promoter has consensus binding sequences for MIG1, a known repressor of transcription in the presence of glucose (Bergkamp et al. 1993). As inulinase is the predominant protein secreted by $K$. marx ianus (Rouwenhorst et al. 1990; Hu et al. 2012), deletion of the encoding locus is expected to permit re-direction of resources for expression and secretion of heterologous proteins. The present work showed that deletion of INU1 had a positive but limited impact on $\mathrm{scFv}$ production in strain No. 8 (Km02-066). This limited effect may have reflected the use of the $\mathrm{KmP}_{M D H 1}$ promoter and the Sc $\alpha$-MFss signal peptide. In Kluyveromyces lactis, the 
Trichoderma reesei $\mathrm{CBH} 1$ secretion signal was more efficient than that of the native $\alpha$-mating factor for directing the secretion of a reporter, enhanced green fluorescent protein (EGFP) (Madhavan and Sukumaran 2014). Use of the endogenous INU1 signal peptide in $K$. marxianus may provide more efficient production by directing the heterologous protein into the secretion pathway typically used by inulinase.

In $K$. marxianus, lysine aminopeptidase activity is higher at $30{ }^{\circ} \mathrm{C}$ than at $20{ }^{\circ} \mathrm{C}$ (Ramírez-Zavala et al. 2004). It would be valuable to assess the in vivo role of various processing enzymes, for instance by suppressing the activity of endogenous proteases by using either protease inhibitors or genetic manipulations. In this study, however production of $\mathrm{scFv}$ increased as temperature elevated, suggesting that the proteases did not seriously affect $\mathrm{scFv}$ production in the conditions tested.

A positive effect of $\mathrm{MgSO}_{4}$ was observed (to some extent) in all strains and conditions, indicating that $\mathrm{MgSO}_{4}$ generally facilitates the production/secretion of intact scFv in $K$ marxianus (Fig. 4a, b). Considering the concentration of $\mathrm{MgSO}_{4}$ in the defined media that typically ranges up to 10 or so, $200 \mathrm{mM}$ of $\mathrm{MgSO}_{4}$ apparently exceeded the nutritional demands of the cell. The addition of divalent metal ions, including $\mathrm{Mg}^{2+}$, has been reported to enhance bacterial cell growth and enzyme production (Venkateswarulu et al. 2017; Shahbazmohammadi and Omidinia 2017). The effect of divalent metal ions may result from changes to membrane permeability (Venkateswarulu et al. 2017). In the present study, we observed drastic increases in antibody secretion in the presence of $200 \mathrm{mM} \mathrm{MgSO}$, a concentration that is ten times higher than that tested in bacteria. While fungal protein secretion pathways differ from those of bacteria, high concentrations of $\mathrm{MgSO}_{4}$ may also affect membrane organization in eukaryotes, facilitating protein secretion and/or stimulating expression of genes that contribute to enhanced protein production and secretion. The effect of $\mathrm{MgSO}_{4}$ significantly differed dependent on strain background, suggesting that it is implicated in the specific cellular processes. Most prominent effect was observed in the genomic integration strain in which $\mathrm{scFv}$ replaced INU1 coding sequence and was expressed under INU1 promoter with INU1 signal peptide, implying that $\mathrm{MgSO}_{4}$ has great impact on inulinase secretion pathway. However, $\mathrm{MgSO}_{4}$ is also likely to be involved in a wide range of fungal cellular and biochemical processes, the exact mechanism of this $\mathrm{MgSO}_{4}$-mediated enhancement of $\mathrm{scFv}$ production remains unclear. Nonetheless, our study demonstrated that there is potential for further enhancing fungal protein production by both genetic and physiological manipulations.

\section{Additional file}

Additional file 1: Table S1. Primers used in this study. Figure S1. Amino acid sequence of scFv. Figure S2. Sequence of codon optimized scFv fragment. Figure S3. Sequence of E02-014 plasmid. Figure S4. Sequence of $\mathrm{KmPMDH}$ 1. Figure S5. Sequence of KmPACO1. Figure S6. Secreted scFv activity per cell amount.

\section{Abbreviations}

TCA: tricarboxylic acid; sCFv: single-chain antibody; CRISPR: Clustered Regularly Interspaced Short Palindromic Repeat; CRISPR-Cas9: Clustered Regularly Interspaced Short Palindromic Repeat (CRISPR) — associated protein; $\mathrm{CHO}$ : Chinese hamster ovary; IgGs: large immunoglobulins; HyHEL-10: anti-chicken (anti-hen) egg white lysozyme antibody; PVDF: polyvinylidene fluoride; NHEJ: non-homologous end-joining; EGFP: enhanced green fluorescent protein.

\section{Authors' contributions}

YN wrote the manuscript and performed all the experiments. KN and $\mathrm{TH}$ contributed to the interpretation and assisted in the preparation of the manuscript. AK supervised the manuscript. All authors contributed equally in writing this review article. All authors read and approved the final manuscript.

\section{Author details}

${ }^{1}$ Technology Research Association of Highly Efficient Gene Design (TRAHED), 7-1-49 Minatojimaminamimachi, Chuo-ku, Kobe, Hyogo 650-0047, Japan. ${ }^{2}$ Department of Chemical Science and Engineering, Graduate School of Engineering, Kobe University, 1-1 Rokkodai-cho, Nada-ku, Kobe, Hyogo 657-8501, Japan. ${ }^{3}$ Graduate School of Science, Technology and Innovation, Kobe University, 1-1 Rokkodai-cho, Nada-ku, Kobe, Hyogo 657-8501, Japan.

\section{Acknowledgements}

We thank Professors Izumi Kumagai and Mitsuo Umetsu (Tohoku University) for providing sequence data for the scFv-encoding fragment. We also thank Mr. Takanobu Yoshida for technical assistance. This research was supported by the Project Focused on Developing Key Technology for Discovering and Manufacturing Drug for Next-Generation Treatment and Diagnosis from the Japan Agency for Medical Research and Development (AMED), Japan.

\section{Competing interests}

The authors declare that they have no competing of interests.

Availability of data and materials

All datasets supporting the conclusions of the manuscript were included in the article.

Consent for publication

Not applicable.

\section{Ethics approval and consent to participate}

This article does not contain any studies with human participants or animals performed by any of the authors.

Funding

Not applicable.

\section{Publisher's Note}

Springer Nature remains neutral with regard to jurisdictional claims in published maps and institutional affiliations.

Received: 25 February 2018 Accepted: 5 April 2018

Published online: 12 April 2018 


\section{References}

Bergkamp RJM, Bootsman TC, Toschka HY, Mooren ATA, Kox L, Verbakel JMA, Geerse RH, Planta RJ (1993) Expression of an a-galactosidase gene under control of the homologous inulinase promoter in Kluyveromyces marxianus. Appl Microbiol Biotechnol 40:309-317

Brachmann CB, Davies A, Cost GJ, Caputo E, Li J, Hieter P, Boeke JD (1998) Designer deletion strains derived from Saccharomyces cerevisiae S288C: a useful set of strains and plasmids for PCR-mediated gene disruption and other applications. Yeast 14(2):115-132

Buckholz RG, Gleeson MA (1991) Yeast systems for the commercial production of heterologous proteins. Nat Biotechnol 9:1067-1072. https://doi. org/10.1038/nbt1191-1067

Çelik E, Çalık P (2012) Production of recombinant proteins by yeast cells. Biotechnol Adv 30:1108-1118. https://doi.org/10.1016/j. biotechadv.2011.09.011

Damasceno LM, Pla I, Chang HJ, Cohen L, Ritter G, Old L, Batt CA (2004) An optimized fermentation process for high-level production of a singlechain Fv antibody fragment in Pichia pastoris. Protein Expr Purif 37:18-26. https://doi.org/10.1016/j.pep.2004.03.019

Fonseca GG, Heinzle E, Wittmann C, Gombert AK (2008) The yeast Kluyveromyces marxianus and its biotechnological potential. Appl Microbiol Biotechnol 79:339-354. https://doi.org/10.1007/s00253-008-1458-6

Gietz D, St Jean A, Woods RA, Schiestl RH (1992) Improved method for high efficiency transformation of intact yeast cells. Nucleic Acids Res 20:1425

Hong J, Wang Y, Kumagai H, Tamaki H (2007) Construction of thermotolerant yeast expressing thermostable cellulase genes. J Biotechnol 130:114-123. https://doi.org/10.1016/j.jbiotec.2007.03.008

Hong SJ, Kim HJ, Kim JW, Lee DH, Seo JH (2014) Optimizing promoters and secretory signal sequences for producing ethanol from inulin by recombinant Saccharomyces cerevisiae carrying Kluyveromyces marxianus inulinase. Bioprocess Biosyst Eng 38:263-272. https://doi.org/10.1007/ s00449-014-1265-7

Hu N, Yuan B, Sun J, Wang SA, Li FL (2012) Thermotolerant Kluyveromyces marxianus and Saccharomyces cerevisiae strains representing potentials for bioethanol production from Jerusalem artichoke by consolidated bioprocessing. Appl Microbiol Biotechnol 95:1359-1368. https://doi. org/10.1007/s00253-012-4240-8

Huang M, Bao J, Nielsen J (2014) Biopharmaceutical protein production by Saccharomyces cerevisiae: current state and future prospects. Pharm Bioprocess 2:167-182. https://doi.org/10.4155/pbp.14.8

Inokuma K, Ishii J, Hara KY, Mochizuki M, Hasunuma T, Kondo A (2015) Complete genome sequence of Kluyveromyces marxianus NBRC1777, a nonconventional thermotolerant yeast. Genome Announce 3:e00389-15. https://doi.org/10.1128/genomeA.00389-15

Jain SC, Jain PC, Kango N (2012) Production of inulinase from Kluyveromyces marxianus using dahlia tuber extract. Braz J Microbiol 43:62-69. https:// doi.org/10.1590/S1517-83822012000100007

Jevševar S, Gaberc-Porekar V, Fonda I, Podobnik B, Grdadolnik J, Menart V (2005) Production of nonclassical inclusion bodies from which correctly folded protein can be extracted. Biotechnol Prog 21:632-639. https://doi. org/10.1021/bp0497839

Lai T, Yang Y, Ng SK (2013) Advances in mammalian cell line development technologies for recombinant protein production. Pharmaceuticals 6:579-603. https://doi.org/10.3390/ph6050579

Lane MM, Morrissey JP (2010) Kluyveromyces marxianus: a yeast emerging from its sister's shadow. Fungal Biol Rev 24:17-26. https://doi.org/10.1016/j. fbr.2010.01.001

Lertwattanasakul N, Rodrussamee N, Suprayogi Limtong S, Thanonkeo P, Kosaka T, Yamada M (2011) Utilization capability of sucrose, raffinose and inulin and its less-sensitiveness to glucose repression in thermotolerant yeast Kluyveromyces marxianus DMKU 3-1042. AMB Express 1:20. https:// doi.org/10.1186/2191-0855-1-20

Maccani A, Landes N, Stadlmayr G, Maresch D, Leitner C, Maurer M, Gasser B, Ernst W, Kunert R, Mattanovich D (2014) Pichia pastoris secretes recombinant proteins less efficiently than Chinese hamster ovary cells but allows higher space-time yields for less complex proteins. Biotechnol J 9:526-537. https://doi.org/10.1002/biot.201300305
Madhavan A, Sukumaran RK (2014) Promoter and signal sequence from filamentous fungus can drive recombinant protein production in the yeast Kluyveromyces lactis. Bioresour Technol 165:302-308. https://doi. org/10.1016/j.biortech.2014.03.002

Melorose J, Perroy R, Careas S (1986) Protein secretion from Saccharomyces cerevisiae directed by the prepro-a-factor leader region. J Biol Chem 261:5858-5865. https://doi.org/10.1017/CBO9781107415324.004

Nambu-Nishida Y, Nishida K, Hasunuma T, Kondo A (2017) Development of a comprehensive set of tools for genome engineering in a cold- and thermo-tolerant Kluyveromyces marxianus yeast strain. Sci Rep 7:8993. https://doi.org/10.1038/s41598-017-08356-5

Nielsen J (2013) Production of biopharmaceutical proteins by yeast. Bioengineered 4:207-211. https://doi.org/10.4161/bioe.22856

Raimondi S, Zanni E, Amaretti A, Palleschi C, Uccelletti D, Rossi M (2013) Thermal adaptability of Kluyveromyces marxianus in recombinant protein production. Microb Cell Fact 12:34. https://doi.org/10.1186/1475-2859-12-34

Ramírez-Zavala B, Mercado-Flores Y, Hernández-Rodríguez C, Villa-Tanaca L (2004) Purification and characterization of a lysine aminopeptidase from Kluyveromyces marxianus. FEMS Microbiol Lett 235:369-375. https://doi. org/10.1016/j.femsle.2004.05.009

Rouwenhorst RJ, Visser LE, Van Der Baan AA, Scheffers WA, Van Dijken JP (1988) Production, distribution, and kinetic properties of inulinase in continuous cultures of Kluyveromyces marxianus CBS 6556. Appl Environ Microbiol 54:1131-1137

Rouwenhorst RJ, Hensing M, Verbakel J, Scheffers WA, Van Dijken JP (1990) Structure and properties of the extracellular inulinase of Kluyveromyces marxianus CBS 6556. Appl Environ Microbiol 56:3337-3345

Schabort DTWP, Letebele PK, Steyn L, Kilian SG, du Preez JC (2016) Differential RNA-seq, multi-network analysis and metabolic regulation analysis of Kluyveromyces marxianus reveals a compartmentalised response to xylose. PLoS ONE 11:e0156242. https://doi.org/10.1371/journal. pone. 0156242

Shahbazmohammadi H, Omidinia E (2017) Medium optimization for improved production of dihydrolipohyl dehydrogenase from bacillus sphaericus PAD-91 in Escherichia coli. Mol Biotechnol 59:260-270. https://doi. org/10.1007/s12033-017-0013-z

Swartz JR (2001) Advances in Escherichia coli production of the rapeutic proteins. Curr Opin Biotechnol 12:195-201

Tsumoto K, Nishimiya Y, Kasai N, Ueda H, Nagamune T, Ogasahara K, Yutani K, Tokuhisa K, Matsushima M, Kumagai I (1997) Novel selection method for engineered antibodies using the mechanism of Fv fragment stabilization in the presence of antigen. Protein Eng 10:1311-1318

Venkateswarulu TC, Prabhakar KV, Kumar RB (2017) Optimization of nutritional components of medium by response surface methodology for enhanced production of lactase. 3. Biotech 7:202. https://doi.org/10.1007/ s13205-017-0805-7

Wagner JM, Alper HS (2016) Synthetic biology and molecular genetics in nonconventional teasts: current tools and future advances. Fungal Genet Bio 89:126-136. https://doi.org/10.1016/j.fgb.2015.12.001

Yokota T, Milenic DE, Whitlow M, Schlom J (1992) Rapid tumor penetration of a single-chain Fv and comparison with other immunoglobulin forms. Cancer Res 52:3402-3408

\section{Submit your manuscript to a SpringerOpen ${ }^{\circ}$ journal and benefit from:}

- Convenient online submission

- Rigorous peer review

- Open access: articles freely available online

- High visibility within the field

- Retaining the copyright to your article

Submit your next manuscript at $>$ springeropen.com 